\title{
Transformer Characteristics of Linear Motor-Transformer Apparatus
}

\author{
Nobuo Fujii ${ }^{1}$, Shuhei Kanamitsu ${ }^{1}$, Takeshi Mizuma ${ }^{2}$ \\ ${ }^{1}$ Faculty of Information Science and Electrical Engineering, Kyushu University, Fukuoka, Japan \\ ${ }^{2}$ National Traffic Safety \& Environment Laboratory, Tokyo, Japan \\ E-mail: fujii@ees.kyushu-u.ac.jp \\ Received May 17, 2011; revised July 12, 2011; accepted August 20, 2011
}

\begin{abstract}
The characteristics of linear transformer are studied analytically. The transformer is composed in one of modes of linear motor-transformer apparatus proposed for future wireless light rail vehicle (LRV). The secondary (onboard) power factor can be adjusted at any value by an onboard converter. The equivalent circuit is used to study the transferred power control. The parameters are determined by three-dimensional finite element method (FEM) analysis for one pole-pair model. Under the rated primary (input) and secondary voltage and current, which are specified for linear motor operation, the characteristics of the secondary power factor are cleared. It is also shown that the input capacitor can improve the primary power factor and decrease the input power capacity, but does not change the efficiency. This linear transformer has the efficiency of $91 \%$ and the input power factor of 0.87 when the apparatus without input capacitor is controlled at the secondary power factor of 0.4 .
\end{abstract}

Keywords: Linear Motor, LIM, Linear Transformer, Non-Contact Power Collection, Wireless LRV, FEM, Finite Element Method, Power Factor, Equivalent Circuit

\section{Introduction}

New type of public transportation which is in harmony with environment has been hoped for a future urban transit system [1-3]. We have proposed the linear motor-transformer apparatus for overhead-wireless and non-contact power collection of light rail vehicle (LRV), which has functions the secondary current controlled linear induction motor and linear transformer [2,3]. The transformer and linear motor mode respectively can be switched by only the signal of onboard converter, as shown in Figure 1. The transformer mode without thrust is used for non-contact charge to onboard battery in standstill at station. The charging power and the secondary power factor respectively can be controlled by onboard converter.

In the paper, the power supply characteristics of transformer are studied analytically. The equivalent circuit of transformer is used to compute the characteristics. The parameters in equivalent circuit are obtained by the analysis using the three-dimensional finite element method (FEM). On this transformer, the desirable primary power factor can be obtained by control the amplitude and phase of secondary voltage and current.As functions of secondary power factor, therefore, the characteristics of primary power factor and efficiency are cleared under the limit of primary voltage, primary current and secondary current. The effect of serially or parallel connected input capacitor to obtain a unity power factor at primary side is also studied.

\section{Analytical Model}

Figure 1 shows configuration for each operating mode. For economical configuration, the primary winding on ground is the concentrated single-phase winding supplied by commercial power source. The secondary winding on board is a double-layer distributed winding with hexagonal shape in the end winding. The onboard converter operates as a rectifier for the transformer with single-phase and as a two-phase inverter for the linear motor respectively. Figure 1(a) shows the formation of linear transformer with single phase primary-single phase secondary configuration, in which the thrust does not generate at the position. The model with numerical value for one pole-pair length is shown in Figure 2. The rated 


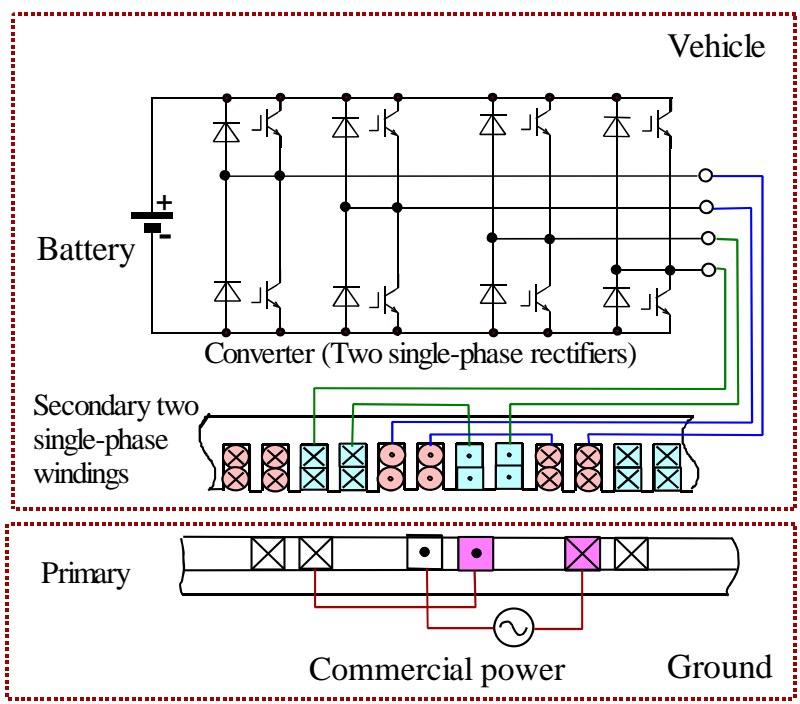

(a)

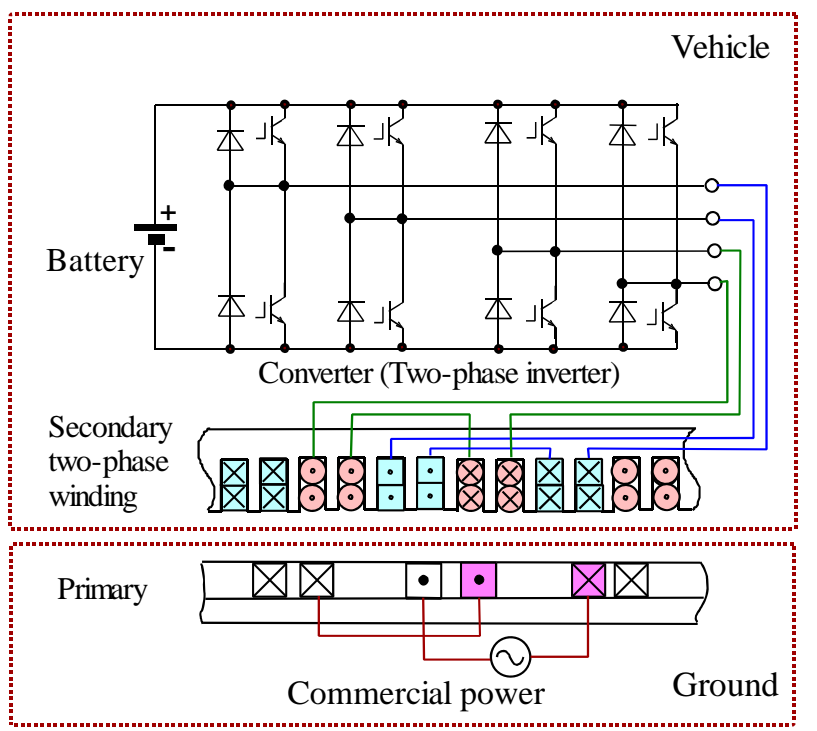

(b)

Figure 1. Linear motor-transformer apparatus.(connection for one pole-pair), (a) Linear-Transformer mode (position for no thrust) (b) Linear-Motor mode (position for maximum thrust).

collecting power per vehicle is $200 \mathrm{~kW}$ and the rated power per one pole-pair length is $4.2 \mathrm{~kW}$ in this design. The main specifications are shown in Table 1. The rated values of voltage and current are determined to obtain the rated thrust in linear motor operation mode because the apparatus is used as both transformer and motor.

Figure 3 shows the model of three-dimensional analysis, in which the FEM tool named JMAG made in Japan is used. The periodic method in the longitudinal direction and the mirror image method in the lateral direction are applied respectively.

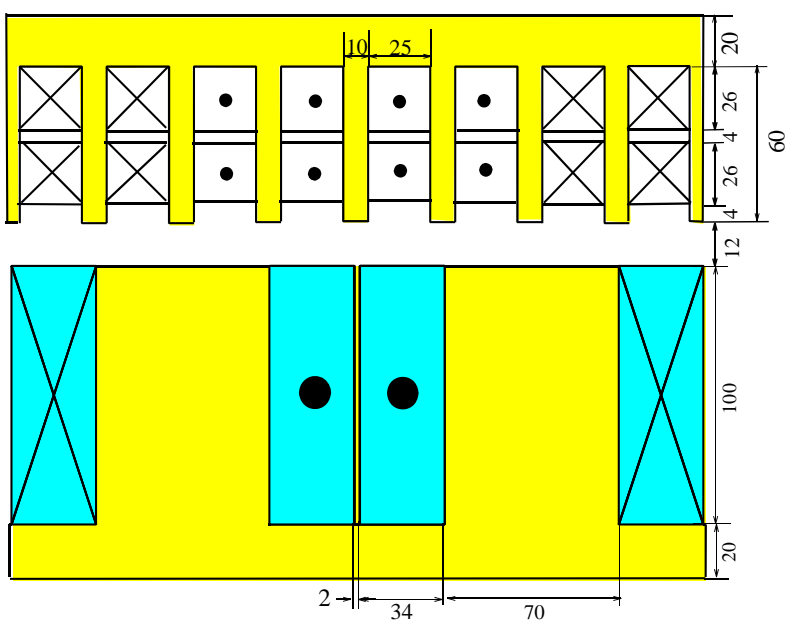

Figure 2. Analytical model and dimension for one pole-pair length.

Table 1. Specifications.

\begin{tabular}{lc}
\hline Rated collecting power / one pole-pair & $P_{2, \text { rated }}=4.2 \mathrm{~kW}$ \\
\hline Ground winding & $50 \mathrm{~Hz}$ \\
Frequency & 32 \\
Turns of coil & $V_{1, \text { rated }}=220 \mathrm{~V}$ \\
Rated voltage / one pole-pair & $I_{1, \text { rated }}=113 \mathrm{~A}$ \\
Rated current & $0.140 \mathrm{~m}$ \\
Pole pitch & $0.012 \mathrm{~m}$ \\
Mechanical clearance & $0.300 \mathrm{~m}$ \\
Width of core & \\
Onboard winding & 8 \\
Turns of coil & $V_{2, \text { rated }}=82 \mathrm{~V}$ \\
Rated voltage / one set of winding & $I_{2, \text { rated }}=110 \mathrm{~A}$ \\
Rated current & 4 \\
Slots / pole & $0.035 \mathrm{~m}$ \\
Slot pitch &
\end{tabular}

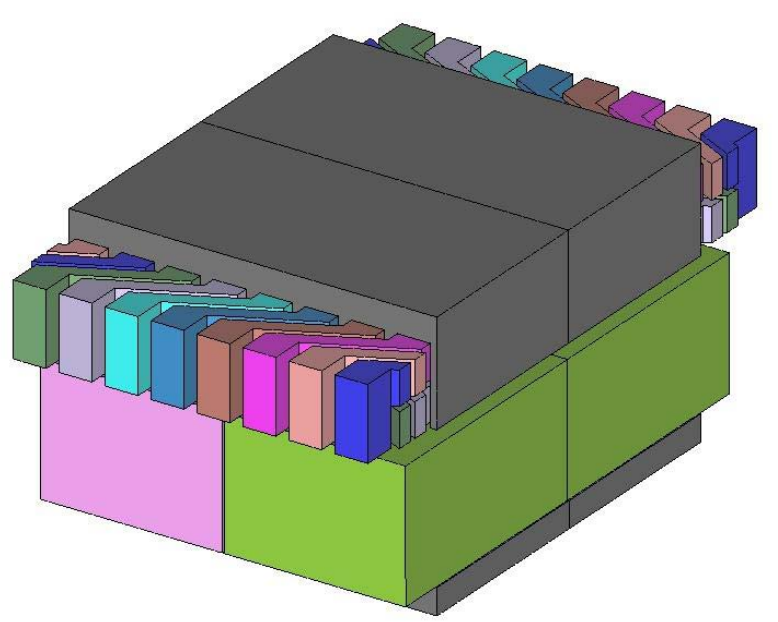

Figure 3. Three-dimensional model of FEM. 


\section{Equivalent Circuit}

The equivalent circuit of this transformer is expressed as shown in Figure 4. The values of element parameters can be estimated by using FEM analysis [4]. The basic electrical circuit can be modified to the machinery equivalent circuit with the leakage inductances, the exciting inductance and the special corrected inductance respectively [4]. Although the expression is intelligible, it is difficult to estimate the equivalent turn ratio of primary to secondary exactly, as shown later in Figure 5. Therefore, in the following study, the equivalent circuit of Figure 4 is used, and the values of elements are dealt with constant values.

When the primary and secondary members are in the position of Figure 2 and the each secondary current is controlled in the same manner, $M_{1, \mathrm{a}}=M_{1, \mathrm{~b}}$ and $L_{2, \mathrm{a}}=L_{2, \mathrm{~b}}$. The values of constants obtained by three-dimen- sional FEM are shown in Table 2.

Figure 5 shows the ratio of primary to secondary on voltage and current. These ratios are not constant and considerably different from the turn ratio of windings.

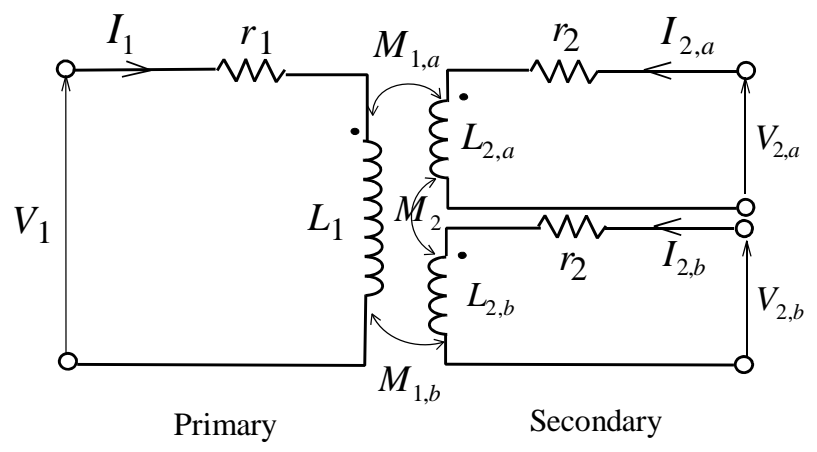

Figure 4. Equivalent circuit for electrical circuit.

Table 2. Values of constants.

\begin{tabular}{ccc}
\hline $\begin{array}{c}\text { Resistance of primary winding }\left(115^{\circ} \mathrm{C}\right) \\
\text { Resistance of secondary winding } \\
\left(115^{\circ} \mathrm{C}\right)\end{array}$ & $r_{1}$ & $0.02357 \Omega$ \\
Reactance of primary winding & $\omega L_{1}$ & $1.9678 \Omega$ \\
$\begin{array}{c}\text { Reactance of secondary winding } \\
\text { Mutual reactance between primary and } \\
\text { secondary }\end{array}$ & $\omega L_{2}$ & $0.4404 \Omega$ \\
$\begin{array}{c}\text { Mutual reactance between secondary and } \\
\text { secondary }\end{array}$ & $\omega M_{1}$ & $0.4666 \Omega$ \\
& & \\
\hline
\end{tabular}

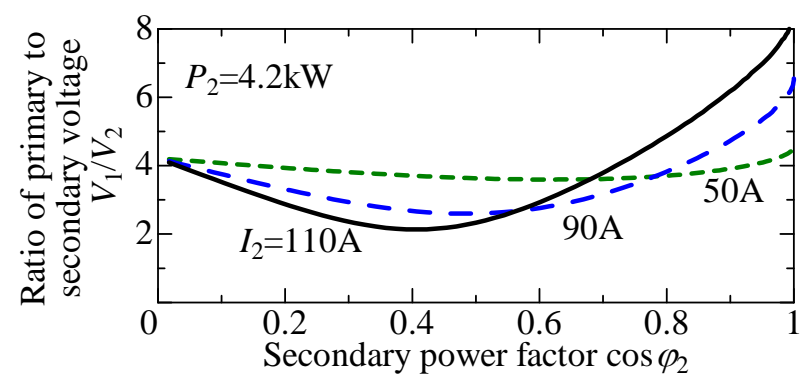

(a)

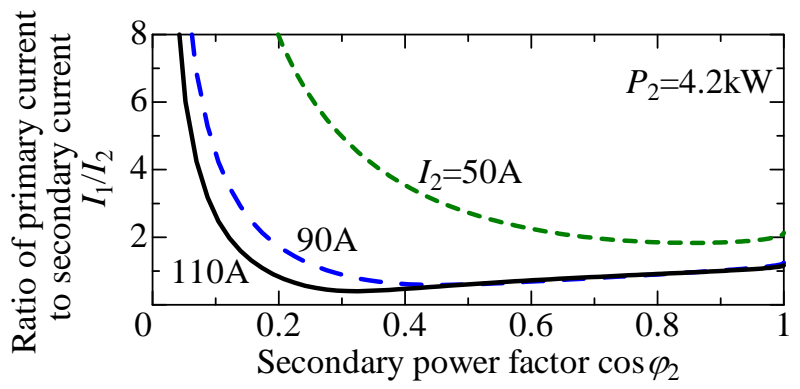

(b)

Figure 5. Ratio of voltage and current between primary and secondary, (a) Voltage (b) Current.

\section{Characteristics}

In the following, the condition of rated collection power of $4.2 \mathrm{~kW}$ is dealt with $M_{1, \mathrm{a}}=M_{1, \mathrm{~b}}=M_{1}, L_{2, \mathrm{a}}=L_{2, \mathrm{~b}}=L_{2}$, $I_{2 \mathrm{a}}=I_{2 \mathrm{~b}}=I_{2}$ and $V_{2 \mathrm{a}}=V_{2 \mathrm{~b}}=V_{2}$.

On this transformer, the converter is used to control the power for charge and to obtain the desirable primary power factor by control the secondary power factor. Although the primary voltage is fixed in practical use, it is hard to consider the fixed voltage in this stage because the relation between primary and secondary voltage changes as shown in Figure 5. The secondary power factor controlled by the converter is, therefore, used as a parameter to clear the characteristics of this type of transformer.

Figure 6 denotes the secondary voltage curves as functions of secondary power factor at the rated secondary power. It is examined on the rated current of $110 \mathrm{~A}$, $90 \mathrm{~A}$ and $50 \mathrm{~A}$ as the secondary current. The secondary voltage increases as secondary power factor or secondary current decreases. As the secondary voltage is limited under the rated voltage of $82 \mathrm{~V}$ which is determined in linear motor operation, the secondary power factor must be over 0.23 at the rated secondary current. When the secondary current is smaller, the secondary voltage increases under the constant output of $4.2 \mathrm{~kW}$, and the usable region of secondary power factor becomes narrow.

Figure 7 shows the primary voltage-secondary power factor characteristics. The primary voltage is not propor- 
tion to the secondary voltage. This is much different from conventional transformer. On the rated secondary current, the primary voltage decreases as secondary power factor decreases in the power factor range higher than 0.5 . As the primary voltage is also limited to the rated value of $220 \mathrm{~V}$, the usable region of secondary power factor is over 0.23 .

Figure 8 represents the primary current characteristics. The primary current increases as the secondary current increases at secondary power factor of 1.0. On the other hand, the primary current decreases as secondary current increases in the region of secondary power factor of 0.3 . This figure shows that the usable region of secondary power factor is from 0.18 to 0.92 on the condition of rated primary current.

From Figures 6-8, the usable region of secondary power factor for control is determined to be from 0.23 to 0.92 from total conditions of rated primary voltage, current and secondary voltage.

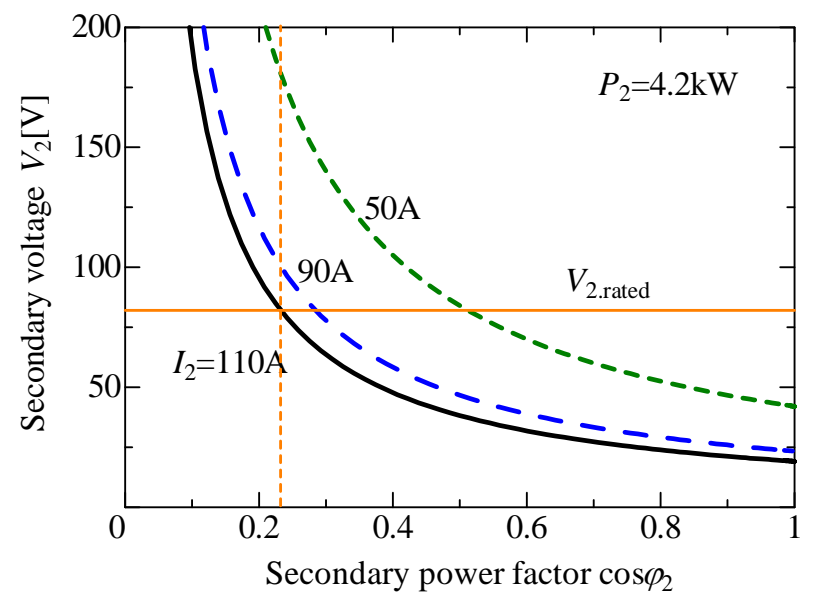

Figure 6. Secondary current-secondary power factor curves.

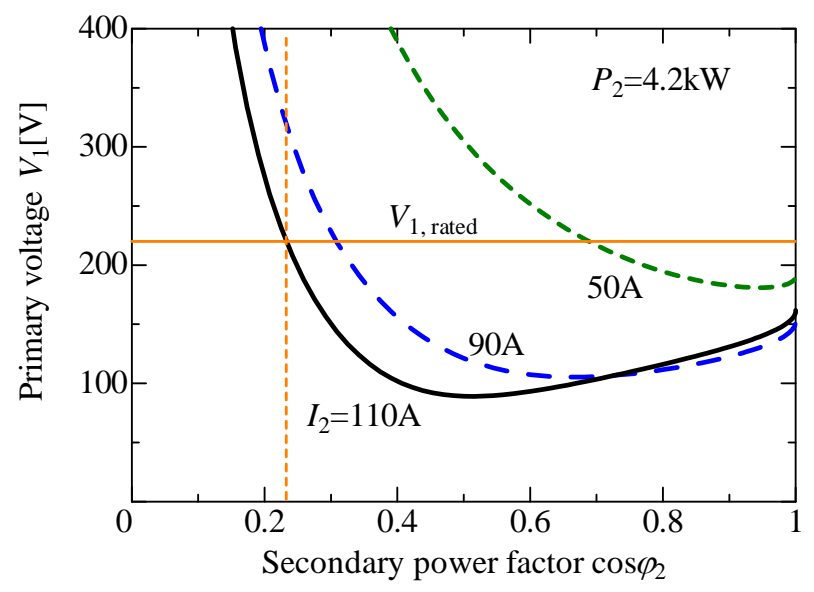

Figure 7. Primary voltage—secondary power factor curves.
Figure 9 denotes the primary power factor characteristics as functions of secondary power factor. When the secondary power factor is controlled to be 1.0 , the primary power factor is very low for any secondary current because the magnetic coupling between primary and secondary member is weak for large air gap. At the rated secondary current, the primary power factor increases as secondary power factor decreases in the region of secondary power factor between 0.4 and 1.0.

The extreme value of primary power factor increases as the secondary current increases. The maximum primary power factor can be 0.87 at the secondary power factor of 0.4 for the rated secondary current.

Figure 10 shows the curves of input capacity as functions of secondary power factor. The minimum capacity is small as the secondary current is large. The rated secondary current of $110 \mathrm{~A}$ and the about secondary power factor of 0.4 gives the minimum capacity. When the secondary power factor is controlled to be 1.0, the input capacity is about four times larger than the minimum value.

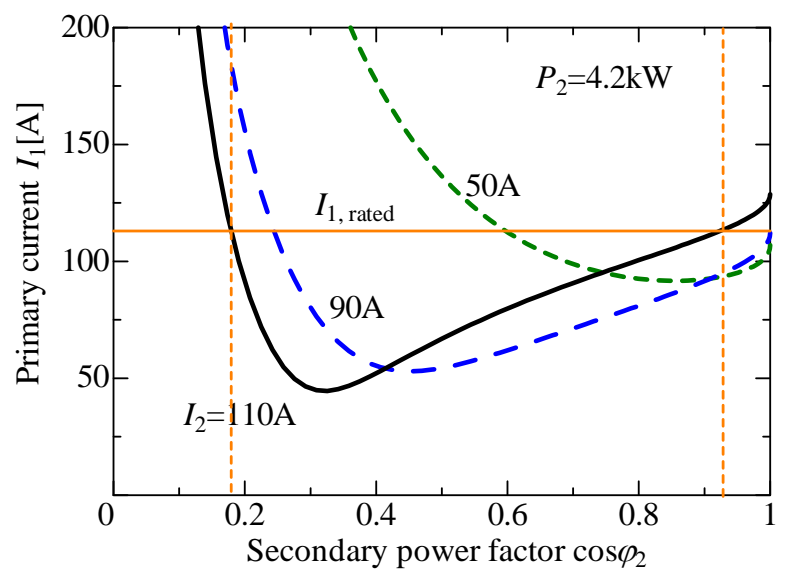

Figure 8. Primary current-secondary power factor curves.

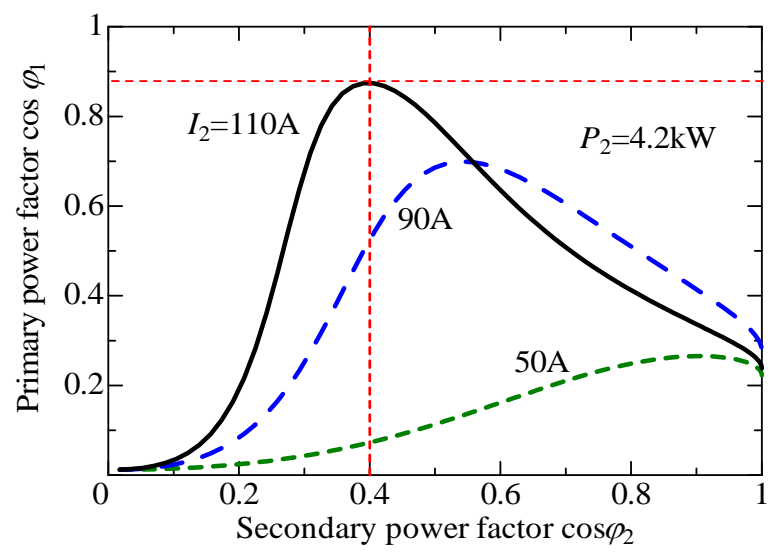

Figure 9. Primary power factor-secondary power factor curves. 
Figure 11 shows the efficiency characteristics, which is computed taking into consideration of only copper loss in the primary and secondary windings. For the rated secondary current of $110 \mathrm{~A}$, in which the current density is $2.21 \mathrm{~A} / \mathrm{mm}^{2}$, the efficiency is $91 \%$ when the secondary power factor is 0.4 .

Figure 12 represents the ratio between primary and secondary copper loss. These losses have influence directly on the efficiency. The current densities of primary and secondary winding are $2.00 \mathrm{~A} / \mathrm{mm}^{2}$ and $2.21 \mathrm{~A} / \mathrm{mm}^{2}$ respectively at rated current. When the secondary current is the rated value of $110 \mathrm{~A}$, the ratio of secondary loss to primary loss increase sharply as the secondary power factor becomes smaller than 1 , and the ratio is 5.7 at secondary power factor of 0.4 . As the influence of secondary resistance is largely on the efficiency, the smaller secondary current density will bring higher efficiency.

\section{Effect of Input Capacity}

In the following, the effect of input capacitor is studied to improve the input capacity. The capacitor is connected in series or parallel at the input side of linear transformer, as shown in Figure 13. In these cases, the input capacity $S_{1}$ is defined as $V_{1} I_{1}$ and the primary power factor is defined as the ratio of input effective power to input apparent power of $V_{1} I_{1}$.

\subsection{Serial Capacitor}

Figure 14 shows the primary power factor curves as functions of capacitance in series connected input capacitor when the output power is the rated value and the secondary power factor is kept at unity. The capacitance with primary power factor of unity depends on value of secondary current. In the following section, the capacitor with capacitance of $2.61 \mathrm{mF}$ for the rated secondary current of $110 \mathrm{~A}, 2.43 \mathrm{mF}$ for $I_{2}=90 \mathrm{~A}$ and $1.83 \mathrm{mF}$ for $I_{2}=50$ A are used respectively for both primary and secondary power factor of unity at the rated output power.

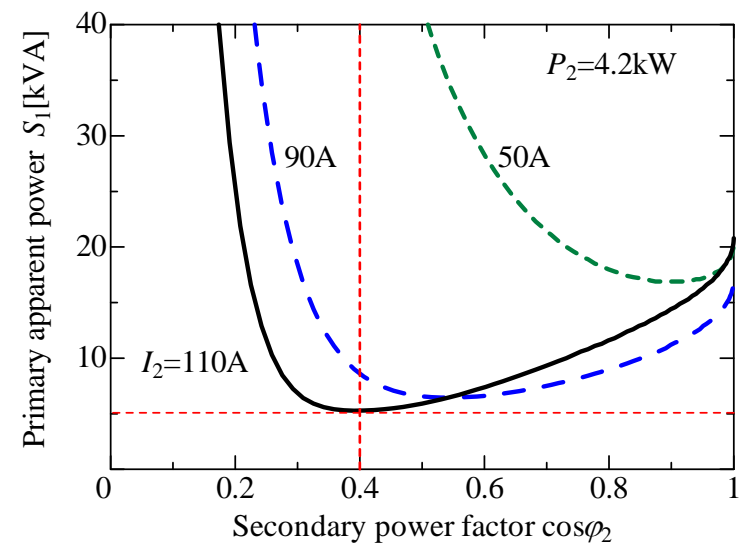

Figure 10. Primary apparent power-secondary power factor curves.

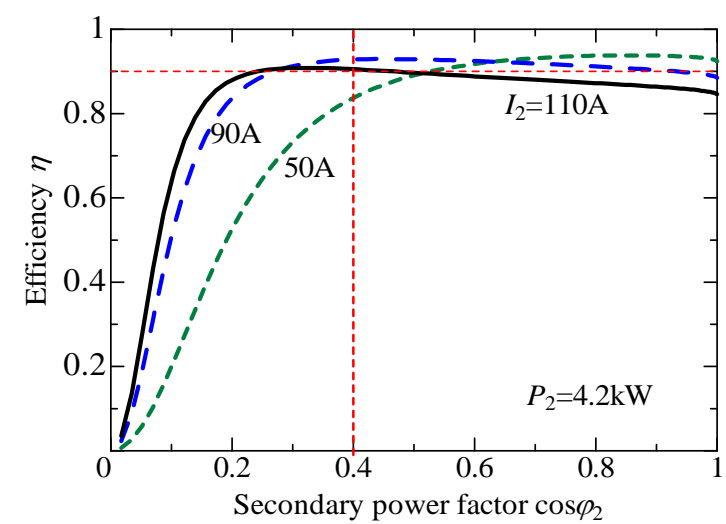

Figure 11. Efficiency—secondary power factor curves.

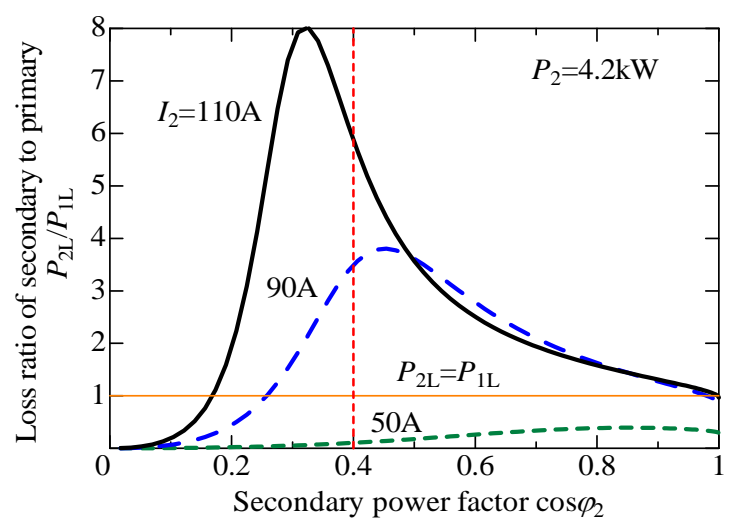

Figure 12. Ratio of secondary loss to primary loss-seconddary power factor curves.

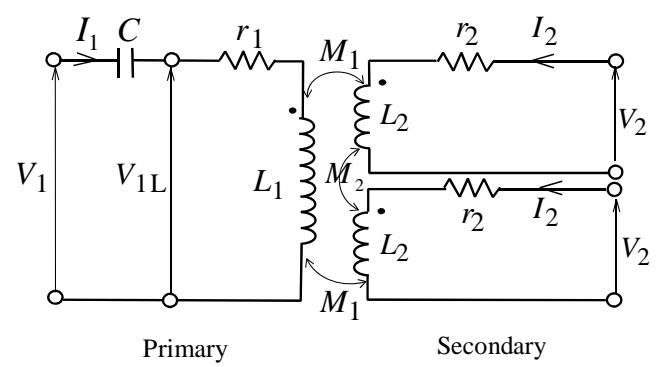

(a)

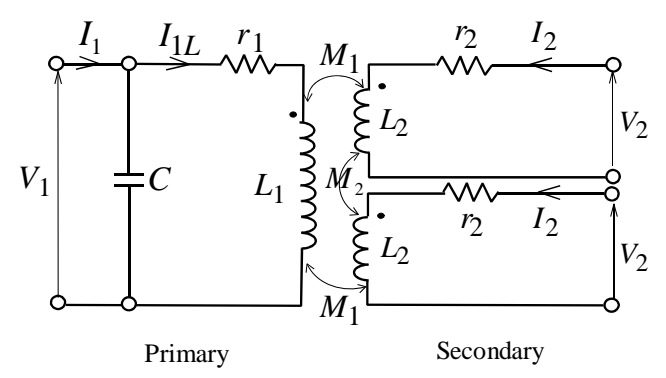

(b)

Figure 13. Model with input capacitor, (a) Serial capacitor, (b) Parallel capacitor. 
In the connection of serial capacitor, the primary power factor is markedly improved as shown in Figure 15. On the rated secondary current of $110 \mathrm{~A}$, the primary power factor is a value above 0.9 in the wide region over the secondary power factor of 0.3 . On the input apparent power shown in Figure 16, it is kept at nearly minimum value in the region over secondary power factor of 0.3 at the rated output power and the secondary current. However, the minimum value of primary apparent power in serial capacitor connection is almost equal to that in the case without input capacitor which is indicated in Figure 10.

Figure 17 represents the efficiency curves in serially connected input capacitor. These values are quite equal to those in case without input capacitor. The copper loss in primary winding is determined by the value of current in primary winding.

The input capacitor does not work to change the current in winding which is determined by the design parameters of apparatus. The capacitor works decrease of primary terminal voltage of apparatus.

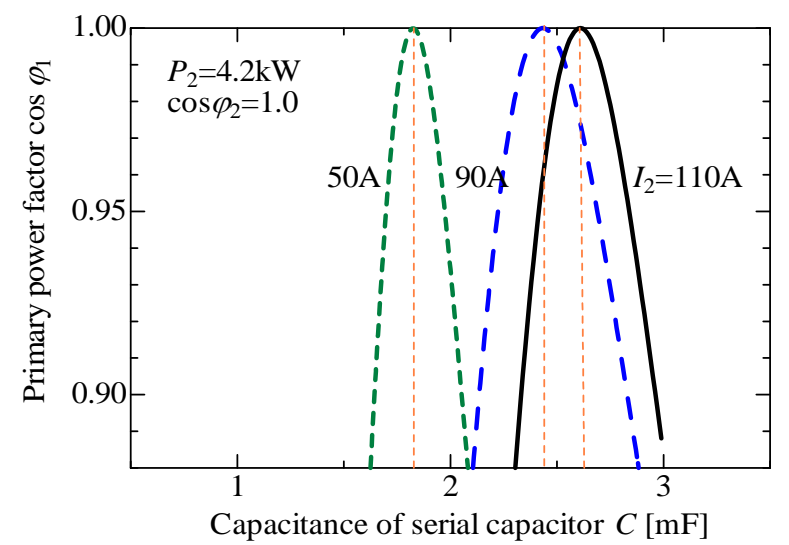

Figure 14. Primary power factor-capacitance of input serial capacitor.

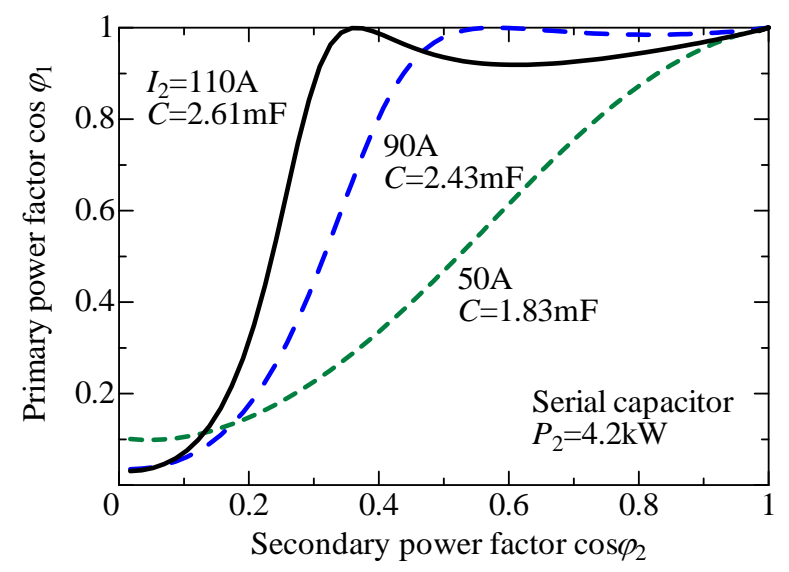

Figure 15. Primary power factor-secondary power factor in case with input serial capacitor.

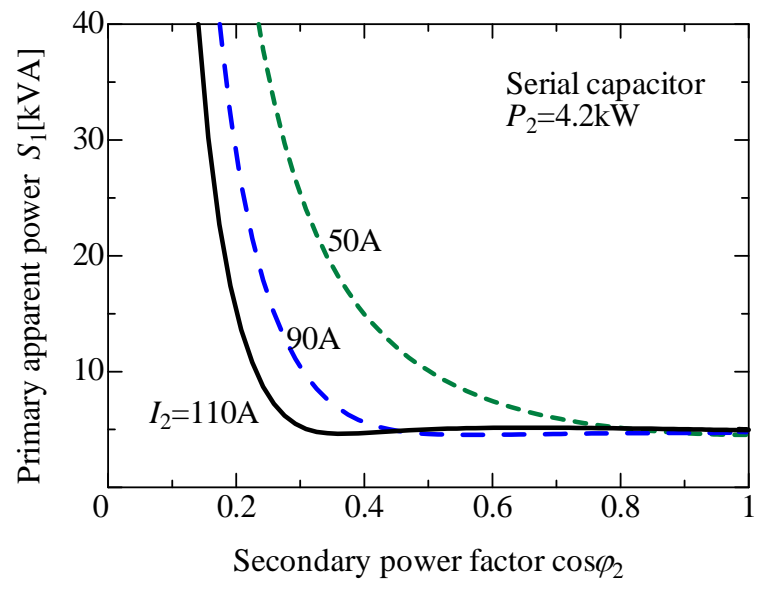

Figure 16. Primary apparent power-secondary power factor in case with input serial capacitor.

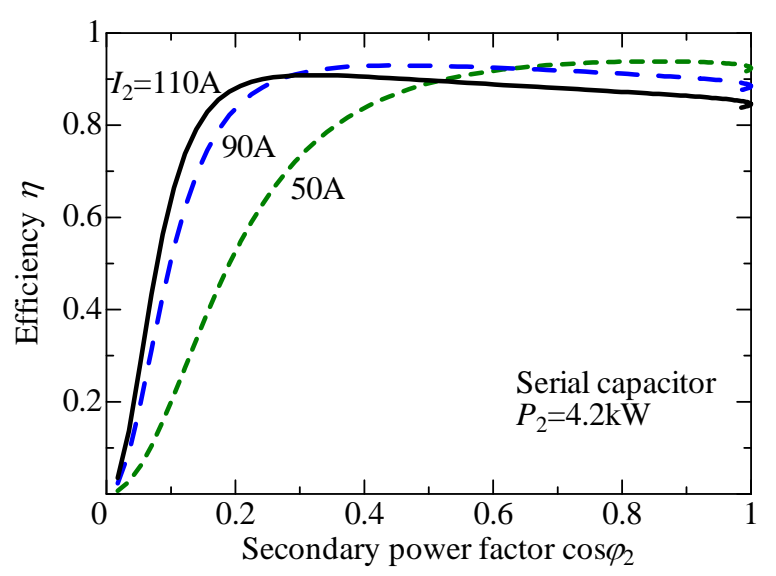

Figure 17. Efficiency-secondary power factor in case with input serial capacitor.

\subsection{Parallel Capacitor}

Figure 18 indicates the capacitance for primary power factor of unity at the rated output power and secondary power factor of unity, which is $2.46 \mathrm{mF}$ for rated secondary current, $2.22 \mathrm{mF}$ for $I_{2}=90 \mathrm{~A}$ and $1.74 \mathrm{mF}$ at $I_{2}=50 \mathrm{~A}$ respectively. The capacitances are slightly smaller than those in series capacitor.

Figure 19 shows the primary power factor as functions of secondary power factor in case with input parallel capacitor. The primary power factor at rated secondary current of $110 \mathrm{~A}$ is about 1.0 in the region between 0.65 and 1.0 in secondary power factor. The primary apparent power characteristics shown in Figure 20 are improved significantly compared to the case without capacitor, as the parallel capacitor works to reduce the input current although it does not work to change the input voltage which is equal to the voltage of primary winding. 


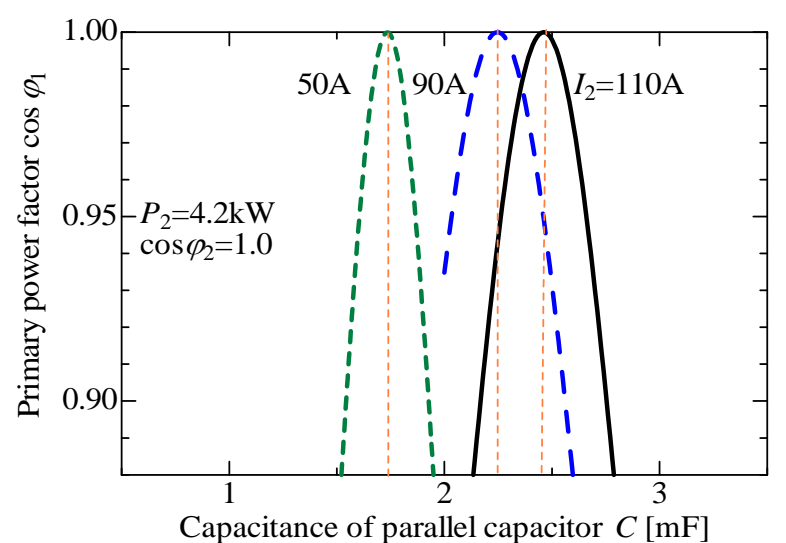

Figure 18. Primary power factor-capacitance of input parallel capacitor.

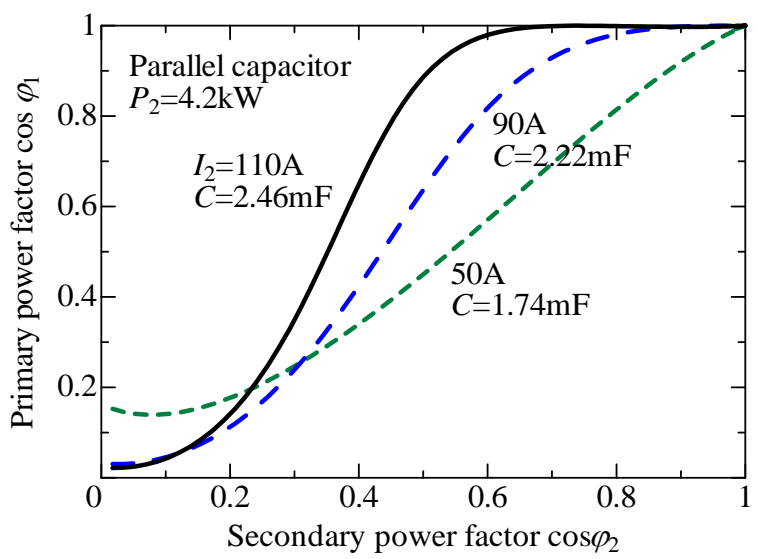

Figure 19. Primary power factor-secondary power factor in case with input parallel capacitor.

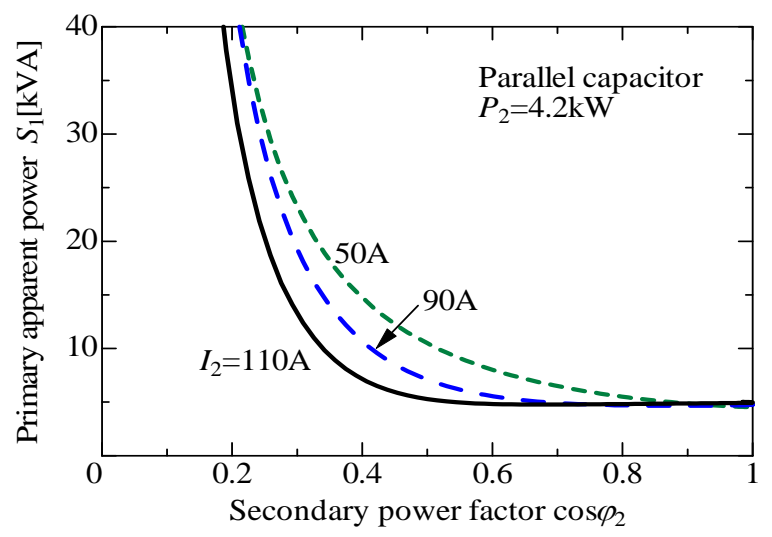

Figure 20. Primary apparent power-secondary power factor in case with input parallel capacitor.

The efficiency characteristics do not change on comparing those without capacitor because neither the current of $I_{1 \mathrm{~L}}$ in Figure 13(b) nor the primary loss is changed by the input capacitor.

\subsection{Comparison}

Figure 21 shows the comparison of input apparent power among in cases with serial capacitor, parallel capacitor and without capacitor. On the region of second- dary power factor with minimum value of primary ap- parent power, the region of serial capacitor is wide com- pared with that of parallel capacitor. The minimum value in case without capacitor is almost equal to that in case of serial or parallel capacitor although the value is ob- tained at the limited secondary power factor of about 0.4 . In this apparatus, the usable region of secondary power factor is over 0.23 , which is obtained from the condition of rated primary voltage, current and secondary voltage for linear motor operation.

Figure 22 indicates the capacity for serial capacitor compared to that for parallel capacitor in the condition rated secondary current with optimum capacitance for input power factor. Considering the capacity and the usable region of secondary power factor, the serial capacitor will be better than parallel capacitor. However, the improvement of the apparent input power is not signifycant in the region between secondary power factor of 0.3 and 0.4, as shown in Figure 21.

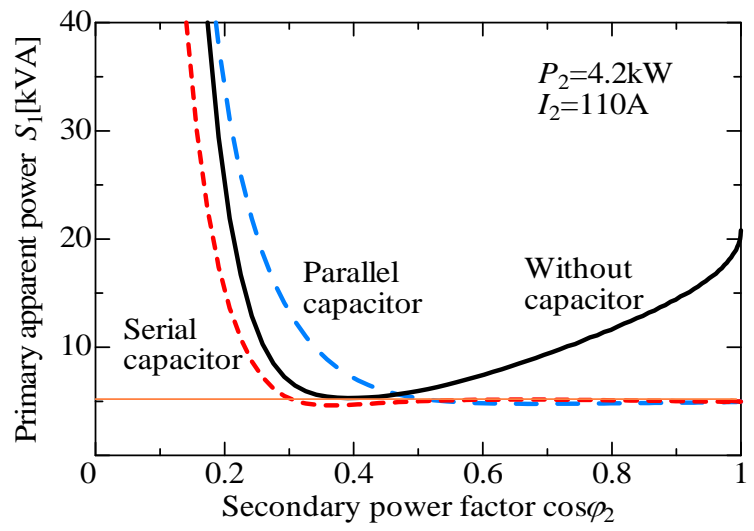

Figure 21. Input apparent power in cases with serial capacitor, parallel capacitor and without capacitor respectively.

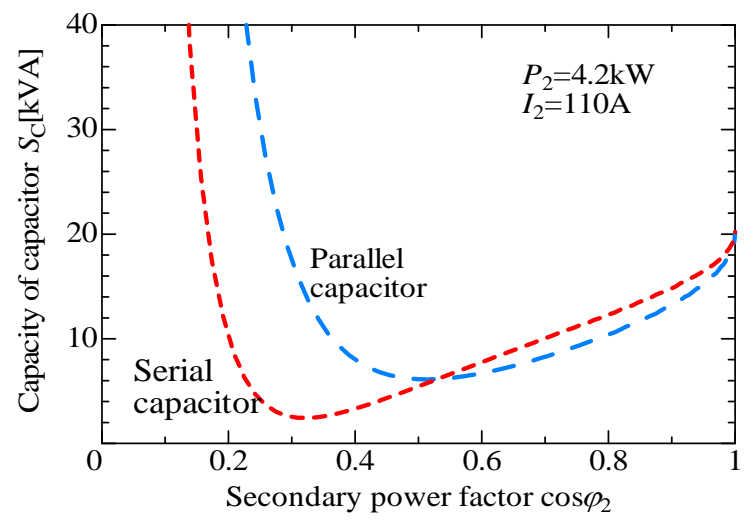

Figure 22. Capacity curves of input capacitor-secondary power factor. 


\section{Conclusions}

1) It is cleared that the secondary power factor can be controlled in the value from 0.23 to 0.92 under the conditions of rated primary voltage, current and secondary voltage for linear motor operation, as this apparatus is used for both linear transformer and linear motor.

2) When the input capacitor is used in series or in parallel, the input power factor of unity can be obtained at the secondary (output) power factor of unity. The effect of input capacitor is recognized in the input apparent power which can be kept at nearly minimum value in the region over secondary power factor of 0.3 in serial capacitor or 0.4 in parallel capacitor at the rated output power and the secondary current.

3) The serial input capacitor will be better than parallel capacitor, considering the capacity and the usable region of secondary power factor.

4) However, the improvement of the apparent input power is not significant compared to the minimum value in case without capacitor. The efficiency characteristics do not change if the input capacitor is removed.
5) In the operation without input capacitor, the efficiency is $91 \%$ and the input power factor is 0.87 when the secondary power factor is controlled at 0.4 .

\section{References}

[1] B. Yang, M. Henke and H. Grotstollen, "Pitch Analysis and Control Design for the Linear Motor of a Railway Carriage,” IEEE IAS Annual Meeting (IAS2001), Chicago, October 2001, pp. 2360-2365.

[2] N. Fujii and T. Mizuma, "Device with Functions of Linear Motor and Non-Contact Power Collector for Wireless Drive,” Transmission IEE of Japan, Vol. 126-D, No. 8, August 2006, pp. 1113-1118 (in Japanese).

[3] N. Fujii and T. Mizuma, "Analytical Study of Special Linear Motor-Transformer for Wireless Tram," Conference Record of The 2008 IEEE Industry Applications Conference, IAS62p1, October 2008, p. 7.

[4] N. Fujii, H. Ashitomi and T. Mizuma, "Equivalent Circuit of Linear Transformer with Function of Linear Motor," ISEF 2009-XIV International Symposium on Electromagnetic Fields in Mechatronics, Electrical and Electronic Engineering, Arras, France, September 2009. 